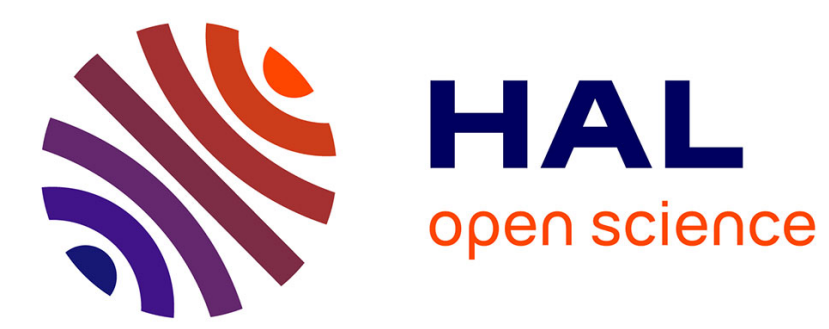

\title{
Social Equity and Ecological Sustainability: New Framework and Directions for the IS Community \\ Claudio Vitari
}

\section{To cite this version:}

Claudio Vitari. Social Equity and Ecological Sustainability: New Framework and Directions for the IS Community. 2013. hal-00969189

\section{HAL Id: hal-00969189}

\section{http://hal.grenoble-em.com/hal-00969189}

Preprint submitted on 2 Apr 2014

HAL is a multi-disciplinary open access archive for the deposit and dissemination of scientific research documents, whether they are published or not. The documents may come from teaching and research institutions in France or abroad, or from public or private research centers.
L'archive ouverte pluridisciplinaire HAL, est destinée au dépôt et à la diffusion de documents scientifiques de niveau recherche, publiés ou non, émanant des établissements d'enseignement et de recherche français ou étrangers, des laboratoires publics ou privés. 


\title{
Social Equity and Ecological Sustainability: New Framework and Directions for the IS Community
}

\author{
Claudio Vitari \\ Grenoble Ecole de Management, Grenoble, France \\ \{claudio.vitari@grenoble-em.com\}
}

\begin{abstract}
Ecological sustainability and social equity are among the United Nations' Millennium Development Goals - but, unfortunately, as the years pass, they are still far from being reached. But concern about these issues has made its way to industry and the IS community. IS play a central role in companies as they are cross-functional and have a strategic role in our current information society.

We argue that it is our responsibility, as IS scholars, to dedicate some of our research efforts toward environmental sustainability and to social equity, and that our teaching, our journals and our associations should also address these two objectives. This article proposes a new framework to facilitate the inclusion of both ecological sustainability and social equity concerns within the IS discipline.
\end{abstract}

Keywords: Social Equity, Ecological Sustainability, IS community.

Research supported by French Rhône Alpes region
(http://www.rhonealpes.fr/).

\section{A human and natural challenge}

Ecological sustainability and social equity are among the Millennium Development Goals officially established by the United Nations (UN) in 2000. Unfortunately several years have passed, but the goals originally set for 2015 are far from being reached. The UN Development Program affirms that environmental sustainability and social equity "are critical to expanding human freedoms for people today and in generations to come. The point of departure is that the remarkable progress in human development over recent decades [...] cannot continue without bold global steps to reduce environmental risks and inequality" - a conclusion that is supported by many indicators of our unsustainable ecology and social inequity, like the fact that Ecological Debt Day falls earlier every year, the annual increases in atmospheric $\mathrm{CO}^{2}$, the depletion of our fossil fuel reserves, the growth in the numbers of both hungry and overweight people, and of revenue inequality.

Ecological Debt Day (the notional day in the year on which the total resources consumed by mankind exceed the Earth's capacity to generate those resources in that year) fell on November $1^{\text {st }}$ in the year 2000, but had moved to August $22^{\text {nd }}$ by 2012. 
The annual growth rate of atmospheric $\mathrm{CO}^{2}$ had increased to $2.36 \mathrm{ppm}$ by 2010 , raising the atmospheric $\mathrm{CO}^{2}$ concentration from around $370 \mathrm{ppm}$ in 2000 to 389.6 ppm in 2010 and reflecting the rate of fossil fuel depletion, with conventional crude oil production peaking in 2006. The number of hungry people in the world was 868 million in 2010-2012 (having been 919 million in 1999-2000), but even more people were overweight. In terms of comparative income levels, the number of 'high net worth' individuals increased from 7.2 million in 2000 to 11 million in 2011 - but at the same time, $50 \%$ of the world's population survives - somehow - on less than $\$ 2.50$ a day and $80 \%$ manage on less than $\$ 10$ a day.

These concerns have trickled through to industry, e.g. with increasing numbers of commercial organizations signing the UN Global Compact that requires them to embrace the UN's universal principles and run their businesses in globally enlightened ways. At the same time, Information System (IS) people have also become more concerned: some have responded to the issue of ecological sustainability via 'Green IT' initiatives $[10]^{1}$ - although we argue that the contribution IS makes to ecological sustainability could go much further than Green IT [8] - while others have responded to the social equity issue via 'Free Software', although other IS initiatives exist in this area too [9]. Given this context, we question under what conditions and to what extent IS can increase ecological sustainability and social equity.

IS play central roles in companies, as they are cross-functional and have very high strategic value in contemporary human society - which has been called the "information society" [11] - and so are in a favorable position to help transform both business and society at large to make them more compatible with the aims of ecological sustainability and of social equity. The academic IS community has already received a call of duty to address ecological sustainability issues [10], but cannot afford to be only thus engaged: we argue that IS scholars should also enhance their sensitivity about social inequity and act in consequence. This article proposes the launch of an initiative for the IS community to engage in both ecological sustainability and social equity.

If "it is our responsibility, as IS scholars, to dedicate some of our research efforts to better understand the role of IS in tackling environmental sustainability" [9], the recognition that ecological sustainability cannot be separated from social equity enshrined in the UN Development Program - extends our responsibility to dedicate at least an equivalent research effort for social equity. Such efforts should also be supplemented by teaching the potential of IS in both social equity and ecological sustainability, and IS journal editors and IS association leaders should get involved, too, in leading the radical change required to achieve these two ambitious objectives.

Our article first describes a novel conceptual framework which could facilitate the reflection and action needed for ecological sustainability and social equity. Second, we propose some research questions that need to be addressed and, finally, advance

1 We wish to explicitly thank Rick Watson, Marie-Claude Boudreau and Adela J. Chen for their inspiring article 'IS and environmental sustainable development' (2010) on which we develop this article. 
some ways in which these issues could be incorporated in teaching, in publishing and in the activities of our academic associations.

\section{IS framework for social equity and ecological sustainability}

IS are involved in organizations, organizations in society and society in nature - so IS are at the heart of our framework through which ecological sustainability and social equity could be tackled more effectively.

\subsection{Nature and Ecological Sustainability, Society and Social Equity}

Clearly, nature $(\mathrm{N})$ - the world's material and energy, the necessary precondition for living organisms to exist - is the founding element of any consideration of ecological sustainability (ES). This paper takes the planet Earth as its reference system in thinking about nature, because the ecological sustainability issue is now a planetary issue [2]. Of course, our planet Earth is not isolated in the universe and the exchanges taking place with the outside are necessary for living. For example, Earth receives a huge amount of solar energy every day and radiates heat out into space. But for many other materials and energies, modeling the planet Earth as in isolation does not distort reality too much, in particular when pursuing sustainability.

Ecological sustainability describes the capacity of biological systems to remain diverse, robust and productive over time. Humans are part of these biological systems and need them to live - but at the same time we are changing them at an increasing rate, to the point where a shift in the Earth's biosphere is approaching [1]. But if humans need biological systems to live, the opposite is clearly not true: nature does not depend on humans for its sustainability.

If humans need nature to live, it is also true that they need to gather into societies to live successfully. A society (S) is an ensemble of people who share the same natural environment and enjoy patterns of inter-relationships, and who can benefit from living together, within nature, in ways that would not otherwise be possible on an individual basis. In thinking at the planetary level, our reference society is the world's human society, which shares the environment of the planet Earth.

Social equity (SE) is inextricably linked with society, and describes a social acceptability sentiment which is based on the recognition that all humans should enjoy equivalent human rights, without them necessarily being enshrined in specific laws and regulations. Social equity differs from social equality, in that social equity accepts some level of inequality when strict equality is not socially acceptable.

\subsection{Organizations, Information Systems and IS processes}

Within society, individuals gather into diverse organizations (O) - social entities of humans who have collective goals which they pursue in interaction with the rest of society. For our purposes, an organization can be a government, a corporation or a 
NGO - so there are actually millions of them, which overlap each other: they all exist within nature, and within human society, without which no organization could survive

Within organizations, information systems (IS) are particular structured combinations of material and energy, data, information, processes and people, which allow those involved in ISs (hereinafter 'IS people') to use the available material and energy to process incoming data (directly or indirectly) to produce information - the output such systems pursue.

These IS processes treat data in various ways (like storing, displaying, transmitting them) so information outputs have higher levels of abstraction than those of data inputted into the IS. Such processes can vary considerably, impacting the amount and the kind of data, material and energy inputs required and the amount and kind of material and energy - as well as of information outputs - the IS produces. The way IS processes are organized and performed determines the IS's effectiveness (doing the right thing) and efficiency (doing the thing right) [4].

For our purposes, we stress that this information output is always at the cost of some degradation in the organization's stock of material and energy. Although we distinguish data and information from material and energy, in physical terms information and data remain material and energy - they are just codified in ways that humans can interpret, so we give them special attention as informational level of an IS.

\subsection{Data and Information respectively as informational level input and output of IS processes}

Data (D) are the informational input of an IS, and are characterized by a being at a level of abstraction that is lower than that of the output (i.e., information) - although the level of abstraction is relative to a specific IS, so the information output of one IS can be the data input for another. Data can come directly from inside the IS (ISD) for example where data are stored as software application parameters - or can come from within the organization (OD), as when, for example, data are the prices a sales manager sets, which are then stored in the IS to inform sales staff. Data can also come from society (SD) - for example a government's decisions about levels of value added tax on an organization's products - or from nature (ND), as when air temperature measurements need to be factored in. In practice, the data, required by the average IS, actually come from all these sources: some parts from within the IS, others from the organization, from the society and, finally, from nature.

Information is the informational output of the IS, and it is characterized by being at a higher level of abstraction than that of the input data. As with data, information can remain inside the IS (ISI), for example when information about hardware failure is captured by the IS administrator to assist in that hardware's repair. Information can exit the IS but remain inside the organization (OI), for example when the sales manager receives reports about company sales, or it can exit the organization to the society (SI) - for example when stock price fluctuations are publicly broadcasted by stock exchange organizations. Information can also be directed to nature (NI), for example when instructions are given to police dogs. As with data, some pieces of 
information from the average IS remain within the IS, others are diffused as far as the organization, some are publicized in society and the final pieces transmitted to nature.

\subsection{Lower and Higher Entropy material and energy respectively as physical level input and output of IS processes}

In physical terms, the IS requires the input of a particular combination of material (such as hardware) and energy (e.g., electricity) in order to process data and so produce information. Beyond information, the IS also outputs some material, such as printed paper, and energy, such as heat. The processes that take place in an IS reduce the system's initial state of order, making the material and energy available in the system less effective or useful. The hardware input can breaks down, the electricity input is converted in heat, the white paper is covered with ink. Even if the paper, or other outputs, is recycled, the recycling system cannot be $100 \%$ physically efficient. Moreover, anyway these recycling processes will require more input, for example energy. This new input, to bring back the IS to its initial state of order, raises the issue of the availability of the energy and material outside the IS, thus simply pushing the boundaries of the reference system out.

Entropy is the metrics measuring the level of system's state of order, i.e. its usefulness or effectiveness [5]. A system's entropy increases as its levels of order and thus the availability, usefulness and effectiveness of its material and energy decrease, and entropy decreases as they increase. The processes taking place in a system will increase or decrease its Entropy - but processes that take place in isolated systems can only reduce the initial system's state of order, i.e. raise its entropy level. The slower the processes will reduce the initial system's state of order, the longer the system will function over time.

Hence, concerned about Ecological sustainability, questioning the functioning of our systems over time is crucial. The isolated system perspective facilitates the development of thinking to reduce as far as possible this ineluctable increase in Entropy. For our specific purposes, we talk about Lower Entropy (LE) when we refer to a system's initial state of order, and Higher Entropy (HE) when referring its later or final state of order.

The concept of entropy comes originally from thermodynamics, where is used to explain why some processes - like ice melting in a glass of water - occur spontaneously while others - such as the electrolysis of water - do not. By extension, it explains why processes in isolated systems are not reversible: ice and water do not naturally separate again without new energy input. The entropy in such systems can only remain constant (if nothing happens) or increases, if a process takes place. Although first used to describe energy issues [3], the entropy concept has since been applied to the physical world [2], to information theory [6] and also to economic processes [9].

Given this wide possible applicability, we decided to employ the entropy concept to the physical level of an IS, so that its material and energy inputs carry Lower Entropy (LE) than its material and energy outputs, which hence carry Higher Entropy (HE). The material and energy transformations of physical input into physical output 
that change (i.e., rise) the entropy level of the information system as a whole. Entropy levels relate to specific systems (here, Information Systems), but (as noted above) the material and energy outputs of one IS can be the material and energy inputs for another - so the HE outputs of one IS can also be LE inputs into another.

LE material and energy are the physical means employed to process data into information. Among the material, we will certainly find Information and Communication Technology hardware, and, typically, the energy will be electricity. As with the informational level, LE material and energy can be provided from within the IS (ISLE), for example when old hardware is reused for less demanding tasks; from outside the IS but still within the organization (OLE), for example when empty rooms are used to host an organization's data center; from the society (SLE) beyond the organization, for example when hardware and electricity are purchased from the market, or directly from nature (NLE), for example when the organization harvests photovoltaic electricity to run its computers directly. Thus, in more or less the same way as for data and information, LE material and energy are likely to come from a combination of sources: nature, society, organization and the IS itself.

Higher Entropy (HE) material and energy are the physical outputs of an IS, and their entropy levels are higher than those of its material and energy IS inputs. As with LE material and energy, HE material and energy can remain inside the IS (ISHE), for example when the heat generated by a central processing unit is diffused to adjacent hardware components; can exit the IS but remain inside the organization (OHE), for example when the heat from computers warms the air in offices; can exit the organization and impact society (SHE), such as when obsolete hardware is sold on the second-hand market, or can reach nature directly (NHE), e.g., when broken hardware is allowed to decompose naturally. As for other IS components, in general, part of these HE material and energy outputs remain within the IS, some exits the IS but remains within the organization, some is expelled into society, and the last portion is released to nature (Figure 1 shows the whole IS framework for social equity and ecological sustainability). 


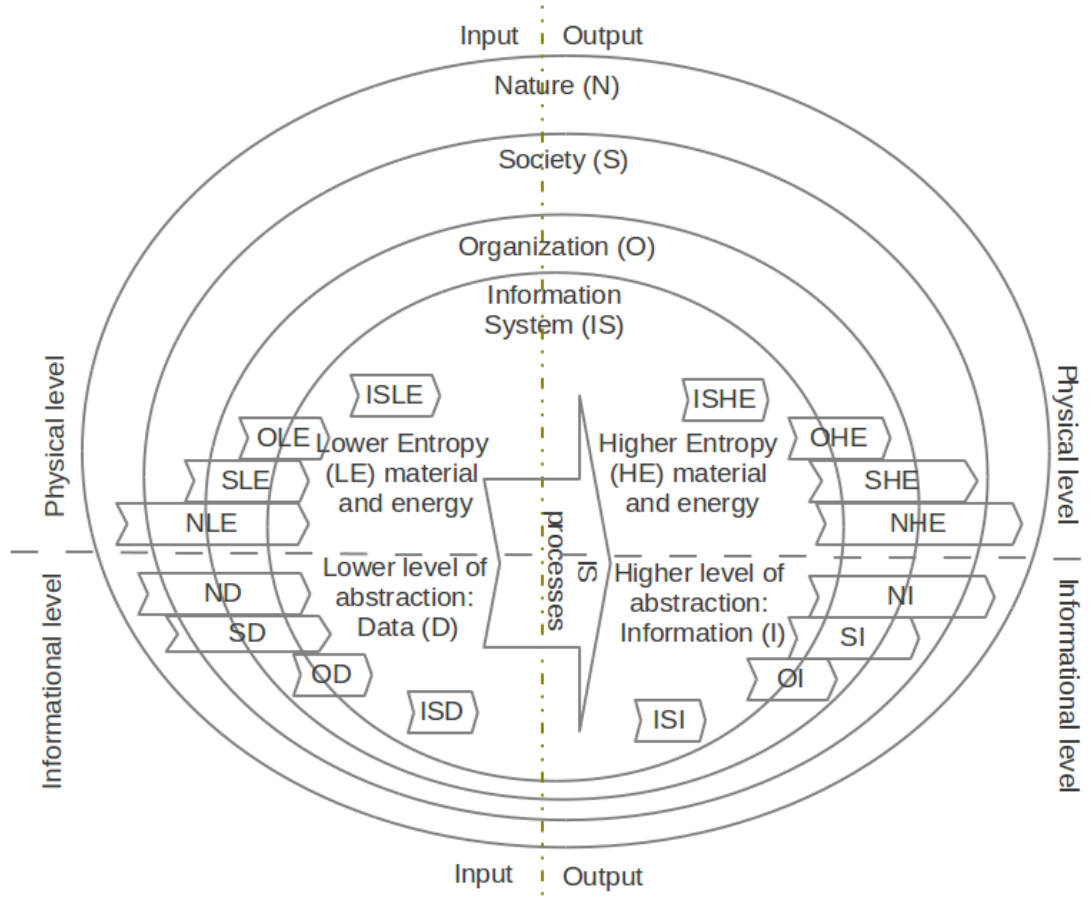

Fig. 1. The IS framework for social equity and ecological sustainability Notes: the figure shows that the Information System (IS) is within the Organization (O), and within the Society (S) and within Nature (N). It separates the two levels of the IS: informational and physical, and the Input and Output of the IS processes, too. In addition, it models how IS transform Lower Entropy (LE) and Data (D) into Higher Entropy (HE) and Information (I). Lower Entropy can come from Nature (NLE), the Society (SLE), the Organization (OLE), the IS itself (ISLE). Data can come from Nature (ND), the Society (SD), the Organization (OD), the IS itself (ISD). Higher Entropy can go to Nature (NHE), the Society (SHE), the Organization (OHE), or stay within the IS itself (ISHE). Information can be diffused to Nature (NI), the Society (SI), the Organization (OI), or, again, remain in the IS itself (ISI)

\section{$3 \quad$ Concluding Thoughts}

The UN has called everyone to contribute to fulfilling the Millennium Development Goals, and to recognize that social equity is inextricable interwoven with ecological sustainability. While social equality is still not a reality, some people have more power than others to help reach these objectives. Through their research, teaching, political influence and media exposure, scholars can play a key role in this ecological and social revolution, by including both environmental sustainability and social equity directly in our research, in our teaching, in our publication outlets and in our academic associations. About research, clear scientific evidences on the roles that IS have to play are still missing, but as far as IS are central in our society, we propose the IS community should develop a new research IS sub-field to tackle the subject and to 
show under what conditions and to what extent IS can increase ecological sustainability and social equity.

Beyond research, changing our teaching is imperative. Many higher education institutions have already created sustainability departments, or now include ecological sustainability on their curricula [10] - but fewer explicitly include the study of social equity. Educational institutions including both sustainability and equity on their IS courses are even rarer. While some initiatives specifying ecological sustainability in IS have been identified - such as at Baruch College, City University, New York [7]we found none that consider the link between IS and social equity. Environmental sustainability and social equity must not be confined to ecology and public policy scholars respectively, but should be seized on as relevant study areas by the whole teaching community.

Finally, those IS leaders who embrace issues of ecological sustainability have been able to propose changes that have reverberated around the entire IS academic community [10], so the same could be true for those who take up social equity questions. In line with the previous pleas for giving ecological sustainability priority, we urge our leaders and our journals' and associations' board to guide IS colleagues towards the quest for social equity, too.

\section{$4 \quad$ References}

1. Barnosky, Anthony D., Elizabeth A. Hadly, Jordi Bascompte, Eric L. Berlow, James H. Brown, Mikael Fortelius, Wayne M. Getz, et al. 2012. "Approaching a State Shift in Earth/'s Biosphere.” Nature 486 (7401) (June 7): 52-58. doi:10.1038/nature11018.

2. Boulding, Kenneth. 1966. “The Economics of the Coming Spaceship Earth.” In Resources for the Future Forum. Washington, DC, USA.

3. Clausius, R. (Rudolf). 2009. The Mechanical Theory of Heat [1879 ]. Cornell University Library.

4. Drucker, P. 2006. "What Executives Should Remember." Harvard Business Review. http://hbr.org/2006/02/what-executives-should-remember/ar/1.

5. Georgescu-Roegen, Nicholas. 1999. The Entropy Law and the Economic Process. iUniverse.

6. Gray, Robert M. 2011. Entropy and Information Theory. Springer.

7. Kannan, Mohan. 2012. "Curricula | Green IT - Sustainable IT Solutions.” Green I.T. http://blsciblogs.baruch.cuny.edu/greenit/curricula/.

8. Pernici, Barbara, Marco Aiello, Jan vom Brocke, Brian Donnellan, Erol Gelenbe, and Mike Kretsis. 2012. "What IS Can Do for Environmental Sustainability: A Report from CAiSE'11 Panel on Green and Sustainable IS.” Communications of the Association for Information Systems 30 (1) (April 1). http://aisel.aisnet.org/cais/vol30/iss1/18.

9. Srivastava, S., and T. Teo. 2007. "E-Government Payoffs: Evidence from Cross-Country Data.” Journal of Global Information Management 15 (4): 20.

10. Watson, Richard T., Marie-Claude Boudreau, and Adela J. Chen. 2010. "Information Systems And Environmentally Sustainable Development: Energy Informatics And New Directions For The Is Community.” MIS Quarterly 34 (1): 23-38.

11. Webster, Frank. 2006. Theories of the Information Society: Third Edition. Taylor \& Francis. 